\title{
Improvement in Hard Magnetic Properties of FePt Films by Introduction of Ti Underlayer
}

\author{
S. C. Chen, P. C. Kuo, S. T. Kuo, A. C. Sun, C. Y. Chou, and Y. H. Fang
}

\begin{abstract}
The FePt/Ti double layer films were prepared by dc magnetron sputtering on corning glass substrates with FePt and Ti targets. The Ti underlayer with 100-nm thickness was deposited at substrate temperature $200{ }^{\circ} \mathrm{C}$, and the FePt magnetic layer, $300 \mathrm{~nm}$, was prepared at temperature from $200{ }^{\circ} \mathrm{C}$ to $600{ }^{\circ} \mathrm{C}$ for direct formation of ordered $\mathrm{L} 1_{0} \mathrm{FePt}$ phase on the $\mathrm{Ti}$ underlayer. $\mathrm{X}$-ray diffraction analysis showed that the [002] axis of Ti grain was perpendicular to the film plane and the FePt grains had a preferred growth of (111) plane parallel to the film plane. The degree of ordering of the FePt films increased as Ti underlayer was introduced. Magnetic property measurements indicated that the in-plane coercivities $\left(\mathrm{Hc}_{\|}\right)$of the FePt/Ti films in which $\mathrm{FePt}$ films was deposited at different temperatures were all higher than that of FePt single layer film without Ti underlayer. When the deposition temperature of $\mathrm{FePt}$ film was fixed at $600{ }^{\circ} \mathrm{C}$, the $\mathrm{Hc}_{\|}$ value of the FePt single layer film was $3.1 \mathrm{kOe}$, and it increased to $7.3 \mathrm{kOe}$ as $100 \mathrm{~nm}$ Ti underlayer was introduced.
\end{abstract}

Index Terms-FePt/Ti double layers film, in-plane coercivity, magnetron sputtering, Ti underlayer.

\section{INTRODUCTION}

$\mathbf{I}$ T IS well known that the equiatomic FePt thin films with the $\mathrm{L} 1_{0}$ ordered structure have extremely high magnetic anisotropy constant $(\mathrm{Ku})$ and large coercivity $(\mathrm{Hc})$, which make FePt thin films attractive as candidate for magnetic recording media [1], [2]. However, in order to obtain films with ordered $\mathrm{L} 1_{0}$ FePt phase, a high-temperature treatment either by substrate heating during deposition or by post-deposition annealing at around $600{ }^{\circ} \mathrm{C}$ [3], [4] is necessary. Since high-temperature treatment results in larger grain size of the film, the ordering temperature of $\mathrm{L} 1_{0} \mathrm{FePt}$ phase must be reduced for application in magnetic recording media. Several works on the lowering of ordering temperature had been reported, such as doping $\mathrm{Zr}$ [5], $\mathrm{Cu}$ [6], $\mathrm{Ag}$ [7], and $\mathrm{N}$ [8] to FePt thin films.

It has been shown that the introduction of the Ti underlayer affects the grain size and out-of-plane coercivity of the CoCrPt recording films [9]. In this paper, we deposited the FePt film on heated substrate in order to form directly ordered $\mathrm{L} 1_{0} \mathrm{FePt}$ hard magnetic phase and investigated the effects of the Ti underlayer

Manuscript received August 31, 2004; revised November 8, 2004. This work was supported by the National Science Council under Grant NSC 92-2216-E-002-020 and by the Ministry of Economic Affairs of Taiwan under Grant 93-EC-17-A-08-S1-0006.

S. C. Chen is with the Department of Mechanical Engineering, De Lin Institute of Technology, Taipei 236, Taiwan, R.O.C. and also with the Center for Nanostorage Research, National Taiwan University, Taipei 106, Taiwan, R.O.C. (e-mail: sscchh@ms28.hinet.net).

P. C. Kuo, S. T. Kuo, A. C. Sun, C. Y. Chou, and Y. H. Fang are with the Institute of Materials Science and Engineering and the Center for Nanostorage Research, National Taiwan University, Taipei 106, Taiwan, R.O.C. (e-mail: pckuo@ntu.edu.tw).

Digital Object Identifier 10.1109/TMAG.2004.842092

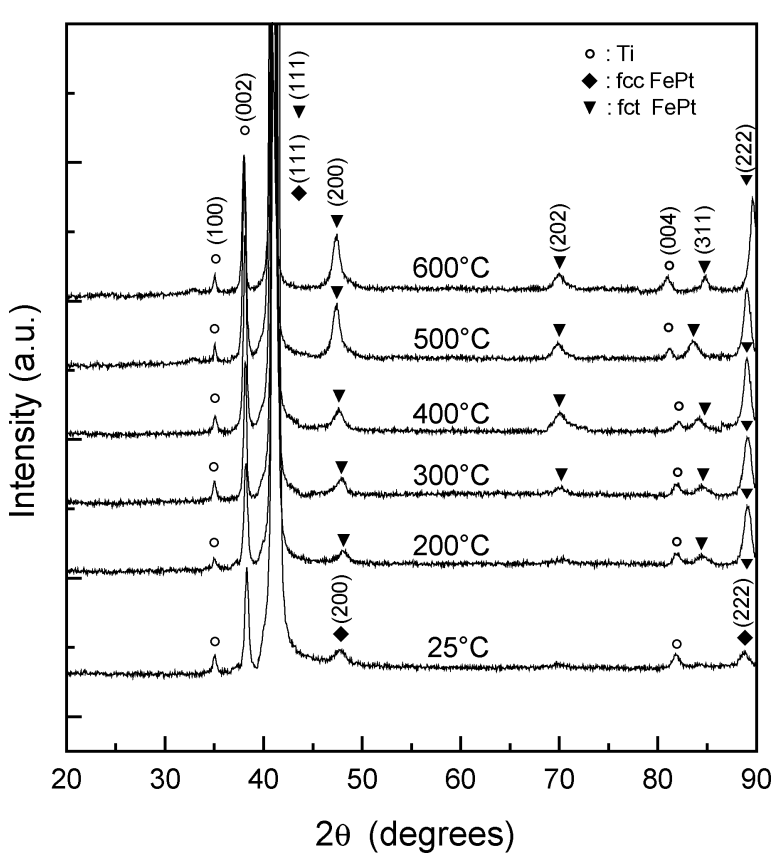

Fig. 1. XRD diffraction patterns of various FePt/Ti double layer films at different substrate temperatures.

and preparation temperature of the FePt film on the degree of ordering, microstructure, and magnetic properties of the film.

\section{EXPERIMENT}

The FePt/Ti double layer films were prepared by dc magnetron sputtering on corning $1737 \mathrm{~F}$ glass substrates with high purity $\mathrm{FePt}(99.99 \%)$ and $\mathrm{Ti}(99.99 \%)$ targets. The base pressure of the sputtering chamber was around $3 \times 10^{-7}$ torr. The FePt magnetic layer was sputtered at an Ar pressure of 10 mtorr and sputtering power of $40 \mathrm{~W}$. The substrate was rotated at $38 \mathrm{r} / \mathrm{min}$ in order to enhance uniform composition of the film. A capped layer of SiNx, 30-nm thickness, was used to cover on the magnetic film to avoid oxidation.

Magnetic properties of the film were measured by using a vibrating sample magnetometer (VSM) with a maximum applied field of $12 \mathrm{kOe}$. The structure of the film was determined by an X-ray diffractometer (XRD). The composition and homogeneity of the film were analyzed by an energy-dispersive spectrum (EDS). The film thickness was measured by an atomic force microscope (AFM) and an $\alpha$-step.

\section{RESUlTS AND DISCUSSION}

Fig. 1 shows the XRD diffraction patterns of FePt (300 nm)/ Ti $(100 \mathrm{~nm})$ films grown at various substrate temperatures 


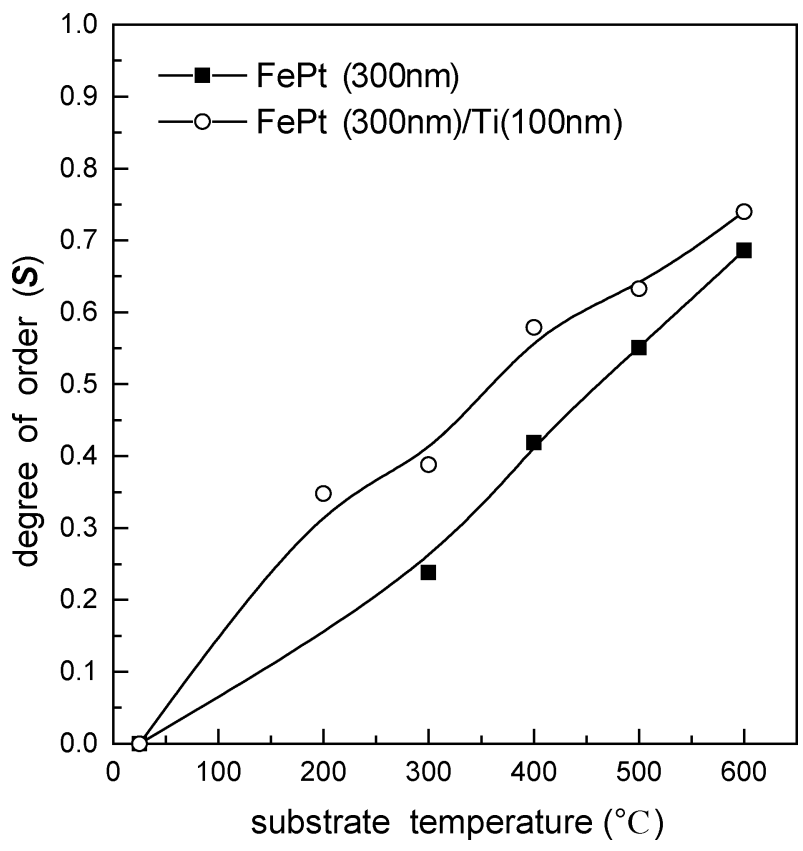

Fig. 2. Degree of ordering of FePt single layer and FePt/Ti double layer films as a function of substrate temperature.

during deposition of FePt film. The structure of FePt film exhibits chemically disordered face-centered-cubic (fcc) $\mathrm{FePt}$ phase as substrate temperature is $25^{\circ} \mathrm{C}$. By increasing the substrate temperature, the $\mathrm{Fe}$ and $\mathrm{Pt}$ atoms will be rearranged, transforming the film into ordered face-centered-tetragonal (fct) $\mathrm{L} 1_{0}$ FePt phase, as shown in Fig. 1. We can see that the [002] axis of Ti grain aligns perpendicular to the film plane direction. The preferred growth of the $\mathrm{L} 1_{0}$ FePt grains (111) is parallel to the film plane and the intensity of the (111) peak enhances with increasing substrate temperature. This indicates that the ordering of $\mathrm{L}_{0} \mathrm{FePt}$ phase is further completed, i.e., the amount of the $\mathrm{L}_{0}$ FePt phase in the FePt layer increases as increasing substrate temperature.

The degree of ordering $(\boldsymbol{S})$ affects the magnetic properties of $\mathrm{FePt} / \mathrm{Ti}$ double layer films. The c/a ratio of lattice parameters of the partially ordered FePt films with different substrate temperature were determined by using X-ray diffraction peaks of (111) and (200) of $\mathrm{L}_{0}$ FePt phase. Hence, degree of ordering can be obtained and expressed as [10]

$$
S^{2}=\frac{1-\left(\frac{c}{a}\right)}{1-\left(\frac{c}{a}\right)_{S_{f}}}
$$

where $(c / a)_{\mathrm{S}_{f}}$ is 0.956 for the fully ordered $\mathrm{FePt}$ films [11]. Fig. 2 shows the degree of ordering of the FePt and FePt/Ti films as a function of substrate temperature. These results have shown that the degree of ordering of the FePt and FePt/Ti films both increase with increasing substrate temperature and the degree of ordering of the FePt/Ti film is higher than that of the single layer FePt film deposited at the same substrate temperature. The $S$ value of $\mathrm{FePt}$ single layer film at substrate temperature of $400{ }^{\circ} \mathrm{C}$ is about 0.4 . It increases to about 0.6 when a Ti underlayer is introduced. The $\mathrm{L}_{0}$ ordered $\mathrm{FePt}$ has the fct structure and its lattice parameters of the $c$ and $a$ axes are $a=3.905 \AA$ and

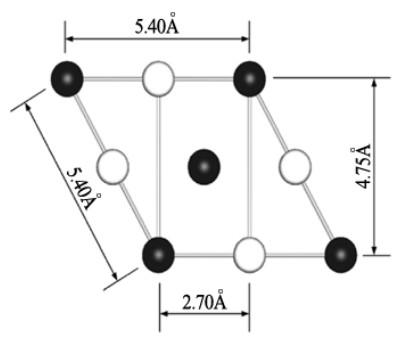

(a)

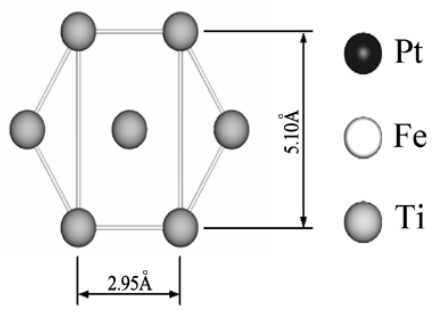

(b)
Fig. 3. Schematic of the lattice misfit between (a) $\mathrm{L} 1_{0} \mathrm{FePt}(111)$ and (b) $\mathrm{Ti}$ (002) planes.

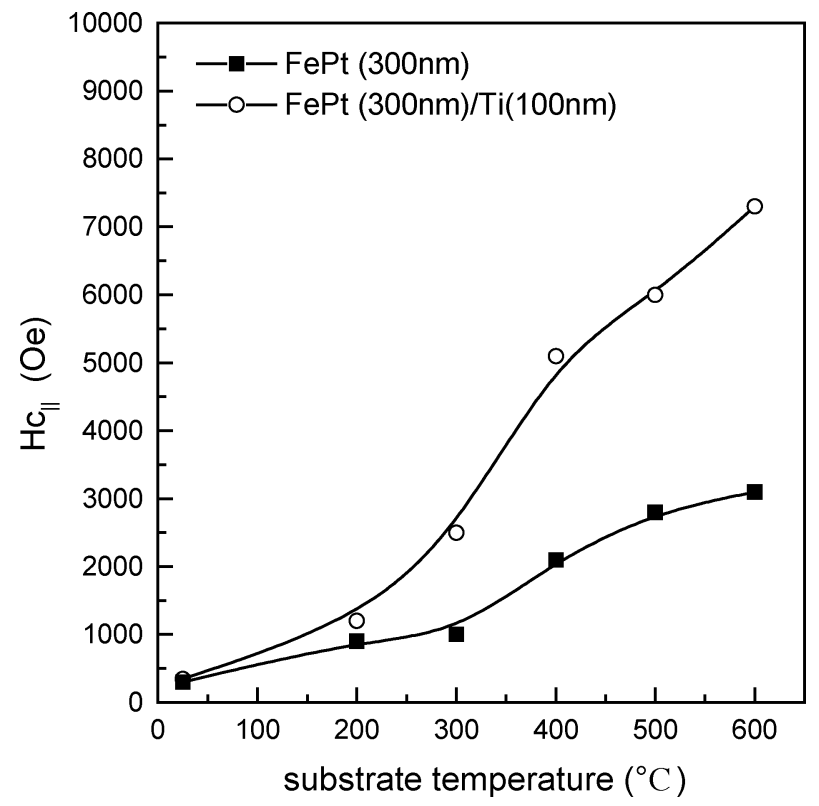

Fig. 4. In-plane coercivity of FePt single layer and FePt/Ti double layer films as a function of substrate temperature.

$c=3.735 \AA$ [11], respectively. In order to reduce the misfit strain energy resulting from the lattice misfit $(\sim 8 \%)$ between the FePt (111) and Ti (002) plane, as shown in Fig. 3(a) and (b), it is speculated that large amount of misfit dislocations and stacking faults need to be presented in the FePt layer. These defects promote the formation of hard magnetic fct $\mathrm{L}_{0} \mathrm{FePt}$ phase, and therefore enhances the degree of ordering of the FePt layer.

Fig. 4 shows the correlations of the in-plane coercivity $\left(\mathrm{Hc}_{\|}\right)$ of the FePt and FePt/Ti films with substrate temperature. Since the FePt grain size increases rapidly as annealing temperature is above $500{ }^{\circ} \mathrm{C}$ [12], the maximum substrate temperature is chosen to be $600{ }^{\circ} \mathrm{C}$ in this study. The $\mathrm{Hc}_{\|}$values of the $\mathrm{FePt}$ single layer films deposited at different temperatures are also increased upon introducing a Ti underlayer of $100 \mathrm{~nm}$ thickness. When the FePt deposition temperature is $600^{\circ} \mathrm{C}$, the $\mathrm{Hc}_{\|}$value of the FePt single layer film is $3.1 \mathrm{kOe}$. It is observed to increase to about $7.3 \mathrm{kOe}$ for the FePt/Ti double layers film. The Ti underlayer has been found to enhance the degree of ordering of the FePt layer and increase the amount of $\mathrm{L} 1_{0} \mathrm{FePt}$ phase in the FePt layer, which in turn will increase the $\mathrm{Hc}_{||}$value of the $\mathrm{FePt}$ film. 


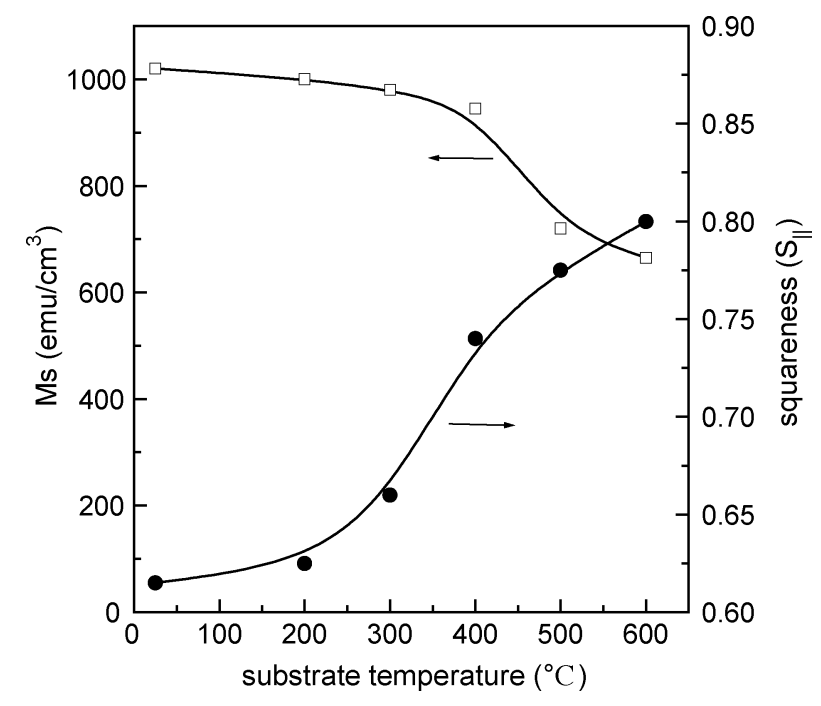

Fig. 5. Saturation magnetization (Ms) and in-plane squareness $\left(\mathrm{S}_{\|}\right)$of FePt/Ti double layers film as a function of the substrate temperature.

Fig. 5 shows the saturation magnetization (Ms) and in-plane squareness $\left(\mathrm{S}_{\|}\right)$of the FePt/Ti double layers film as a function of the substrate temperature. The result shows that the Ms value of the FePt/Ti film is reduced with increasing the substrate temperature. When the substrate temperature is $25^{\circ} \mathrm{C}$, the Ms value of the FePt/Ti film is measured about $1000 \mathrm{emu} / \mathrm{cm}^{3}$. It decreases to about $670 \mathrm{emu} / \mathrm{cm}^{3}$ as the substrate temperature is increased to $600{ }^{\circ} \mathrm{C}$. The Ms value of the fct $\mathrm{L} 1_{0} \mathrm{FePt}$ phase is lower than that of the fcc FePt phase [13]. The reduction of Ms mainly results from increasing $\mathrm{L} 1_{0} \mathrm{FePt}$ phase content in the FePt film when the substrate temperature is increased. Besides, increasing the substrate temperature will also increase the interdiffusion between FePt and $\mathrm{Ti}$, which can also decrease the Ms value. On the other hand, the $S_{\|}$value increases with increasing the substrate temperature, where $S_{\|}$is defined as the ratio of in-plane remanent magnetization $\left(\mathrm{Mr}_{\|}\right)$to $\mathrm{Ms}$. The $\mathrm{S}_{\|}$value increases from 0.62 to 0.8 as the substrate temperature increases from $25^{\circ} \mathrm{C}$ to $600^{\circ} \mathrm{C}$. This has indicated that high substrate temperature favors in improving the in-plane squareness of $\mathrm{FePt} / \mathrm{Ti}$ double layer films.

\section{CONCLUSION}

Both the degree of ordering and $\mathrm{Hc}_{\|}$value of the FePt film are found to increase either by increasing the substrate temperature or/and by introducing a $100 \mathrm{~nm}$ Ti underlayer. Although increasing the substrate temperature enhances the $\mathrm{Hc}_{\|}$and $\mathrm{S}_{\|}$ values of the $\mathrm{FePt} / \mathrm{Ti}$ film, the Ms value is observed to reduce as the substrate temperature increases.

\section{REFERENCES}

[1] J. A. Christodoulides, Y. Zhang, G. C. Hadjipanayis, and C. Fountzoulas, "CoPt and FePt nanoparticles for high density recording media," IEEE Trans. Magn., vol. 36, no. 5, pp. 2333-2335, Sep. 2000.

[2] P. C. Kuo, S. C. Chen, Y. D. Yao, A. C. Sun, and C. C. Chiang, "Microstructure and magnetic properties of nanocomposite FePtCr-SiN thin films," J. Appl. Phys., vol. 91, pp. 8638-8640, 2002.

[3] T. Suzuki and K. Ouchi, "Sputter-deposited (Fe-Pt)-MgO composite films for perpendicular recording media," IEEE Trans. Magn., vol. 37, no. 4, pp. 1283-1285, Jul. 2001.

[4] S. C. Chen, P. C. Kuo, A. C. Sun, C. T. Lie, and C. C. Chiang, "Effects of $\mathrm{Cr}$ and $\mathrm{SiN}$ contents on the microstructure and magnetic grain interactions of nanocomposite FePtCr-SiN thin films," IEEE Trans. Magn., vol. 39, no. 1, pp. 584-589, Jan. 2003.

[5] S.-R. Lee, S. Yang, Y. K. Kim, and J. G. Na, "Rapid ordering of Zr-doped FePt alloy films," Appl. Phys. Lett., vol. 78, pp. 4001-4003, 2001.

[6] T. Maeda, T. Kai, A. Kikitsu, T. Nagase, and J. Akiyama, "Reduction of ordering temperature of an FePt-ordered alloy by addition of Cu," Appl. Phys. Lett., vol. 80, pp. 2147-2149, 2002.

[7] S. S. Kang, D. E. Nikles, and J. W. Harrell, "Synthesis, chemical ordering, and magnetic properties of self-assembled FePt-Ag nanoparticles," J. Appl. Phys., vol. 93, pp. 7178-7180, 2003.

[8] H. Y. Wang, W. H. Mao, X. K. Ma, H. Y. Zhang, Y. B. Chen, Y. J. He, and E. Y. Jiang, "Improvement in hard magnetic properties of FePt films by N addition," J. Appl. Phys., vol. 95, pp. 2564-2568, 2004.

[9] C. J. Sun, G. M. Chow, J. P. Wang, E. W. Soo, Y. K. Hwu, J. H. Je, T. S. Cho, H. H. Lee, and D. Y. Noh, "Long-range order and short-range order study on CoCrPt/Ti films by synchrotron X-ray scattering and extended X-ray absorption fine structure spectroscopy," J. Appl. Phys., vol. 91, pp. 7182-7184, 2002.

[10] Y. Endo, N. Kikuchi, O. Kitakami, and Y. Shimada, "Lowering of ordering temperature for fct Fe-Pt in Fe/Pt multilayers," J. Appl. Phys., vol. 89, pp. 7065-7067, 2001.

[11] P. Villas and L. D. Calvert, Pearson's Handbook of Crystallographic Data for Intermetallic Phase. Metals Park, OH: Amer. Soc. Metals, 1991, vol. 4.

[12] P. C. Kuo, Y. D. Yao, C. M. Kuo, and H. C. Wu, "Microstructure and magnetic properties of the $\mathrm{FePt}_{100-\mathrm{X}} \mathrm{Cr}_{\mathrm{X}}$ thin films," J. Appl. Phys., vol. 87, pp. 6146-6148, 2000.

[13] T. Katayama, T. Sugimoto, Y. Suzuki, M. Hashimoto, P. dc Haan, and J. C. Lodder, "Magneto-optical Kerr rotation spectra in ordered and disordered phase of Fe-Pt alloy films," J. Magn. Magn. Mater., vol. 104-107, pp. 1002-1004, 1992. 